\title{
FEM-BASED COMPARATIVE STUDY OF SQUARE \& RHOMBIC INSERT MACHINING PERFORMANCE DURING TURNING OF AISI-D3 STEEL
}

\author{
Anastasios Tzotzis ${ }^{1}$, Nikolaos Efkolidis ${ }^{1}$, Gheorghe Oancea ${ }^{2}$, Panagiotis Kyratsis ${ }^{1}$ \\ ${ }^{1}$ University of Western Macedonia, Department of Product and Systems Design Engineering, Kila Kozani, GR50100, \\ Greece \\ ${ }^{2}$ Transilvania University of Brasov, Manufacturing Engineering Department, Mihai Viteazu No. 5, Brasov, Romania
}

Corresponding author: Panagiotis Kyratsis, E-mail address: pkyratsis@uowm.gr

\begin{abstract}
Nowadays, employment of the Finite Element Method (FEM) in machining simulation is a common practice to decrease development times and costs, as well as to investigate numerous parameters that affect machining processes. In the present work, the $3 \mathrm{D}$ modelling of AISI-D3 hard turning with both square and rhombic inserts is being presented by utilizing a commercially available Finite Element Analysis (FEA) software. Eighteen tests were carried out based on cutting conditions that are recommended for the used tools. Specifically, three levels of cutting speed $(75 \mathrm{~m} / \mathrm{min}$, $110 \mathrm{~m} / \mathrm{min}$ and $140 \mathrm{~m} / \mathrm{min})$, three levels of feed $(0.12 \mathrm{~mm} / \mathrm{rev}, 0.16 \mathrm{~mm} / \mathrm{rev}$ and $0.20 \mathrm{~mm} / \mathrm{rev})$ and depth of cut equal to $0.40 \mathrm{~mm}$ for all tests, were applied. In order to describe the complex factors that define the model, such as the friction forces, the heat transfer and the pressure due to contact between the tool and the workpiece, a number of acknowledged models were utilized. A comparison of the performance between the two types of tools was made with respect to the developed machining forces and temperature distribution on the workpiece. The findings of the investigation indicate that the specific square tools produce higher values of forces compared to the rhombic ones and approximately the same temperature patterns on the workpiece. The average increase on the produced cutting forces is about $26.4 \%$.
\end{abstract}

Key words: 3D FEM; AISI-D3 turning; Turning inserts; Cutting performance; Machining forces.

\section{INTRODUCTION}

Investigation in machining processes is a research area that amongst others benefits from the advancement of Finite Element Analysis (FEA) software. It is possible to simulate numerous conditions and materials with minimal requirements for costly and time-consuming experimental setups. Davim and Maranhão [1] studied the behavior of AISI-1045 steel during both high speed machining and machining with typical speeds. Authors managed to predict with good precision both plastic strain and plastic strain rate, with the aid of Finite Element
Method (FEM). Fang and Zeng [2] investigated the behavior of tool material H11 by means of FEM. They managed to analyze the chip back-flow angle, the curling radius and thickness of the developed chips, as well as to investigate the effects of land length and second rake angle of the tool on chip formation, fragmentation and developed temperatures. In a similar manner, Tzotzis et al. [3-5] investigated the effects of the tool diameter, the cutting speed and feed on the generated thrust forces and the chip formation when drilling A17075-T6 alloy with solid carbide tooling. A comparison was made between experimental and numerical results, as well as with results from the literature. Furthermore, Tzotzis et al. [6,7] studied the effects of the tool nose radius, the cutting speed, the feed and depth of cut on the generated cutting forces induced during AISI4140 hard turning. In the studies, a combination of Computer Aided Design (CAD) based framework and 3D FEM was utilized. Authors processed the obtained results with well-established mathematical methodologies in order to develop prediction models. Kyratsis et al. [8] employed similar strategies to study the machining of AISI-D3 tool steel and examine the effects of typical cutting conditions on the generated cutting forces for prediction purposes. Moreover, authors analyzed the development of the cutting forces on a wide range of cutting conditions. Nasulea and Oancea $[9,10]$ presented the effects of the material properties of DC05 deep drawing steel with the aid of FEM. Additionally, authors developed a software tool that can be used in incremental sheet forming process simulation. The aforementioned tool uses a CNC file to reveal the interpolation point coordinates of the tool and the positioning time within ANSYS ${ }^{\mathrm{TM}}$.

In the present study, a FEA was realized with DEFORM-3D ${ }^{\mathrm{TM}}$ that investigates the machining performance of rhombic and square inserts when turning AISI-D3. The performance was investigated 
in terms of the generated cutting forces and temperature distribution on the workpiece. Obtained results were used for the development of a 3D Finite Element (FE) model, after comparing them with the results of similar studies for high hardness steel.

\section{MATERIALS AND METHODS}

\subsection{Turning process framework}

The turning insert - tool-holder assemblies of both cases were realized in a 3D CAD environment. This way, the cutting angles were derived, based on the tool-holder geometry. The used tool-holders have ISO designation numbers PCBNR2525M12 and CSDNN2525M12 respectively. Additionally, the used tools are CNGA120408T01020 650 and SNGA120408T01020 650 correspondingly. CNGA inserts are rhombic-shaped with $80^{\circ}$ included angle, whereas the SNGA family includes tools that are square-shaped. Both tool families are used for machining steel and cast iron, however, many manufacturers offer a specific grade that are especially used for machining hardened materials such as AISI-D3 steel. Furthermore, both inserts include a nose radius equal to $0.8 \mathrm{~mm}$ and the same micro-geometry (chamfer width and angle). In this study, the workpiece was designed to be cylindrical with a diameter of $72 \mathrm{~mm}$ and the selected material is AISI-D3 (DIN 1.2080) tool steel, which at high hardness is often used for making punches and dies. Due to the CAD-based assembly, the cutting angles are derived by both the tool-holder parameters and the tool's positioning. That is, the lead angle $(\mathrm{kr})$ is $75^{\circ}$ and $45^{\circ}$ for the CNGA and for the SNGA cases respectively. Moreover, both the rake $(\gamma)$ and inclination $(\lambda)$ angles are negative and equal to $-6^{\circ}$. Figure 1(a) illustrates the tool positioning for the CNGA case, whereas Figure 1(b) for the SNGA case. In addition, Figure 1 depicts the feed direction. Finally, the models of the cutting tools were designed with the aid of an application developed by the authors [11] that is used to automatically generate FEA-ready turning insert models.

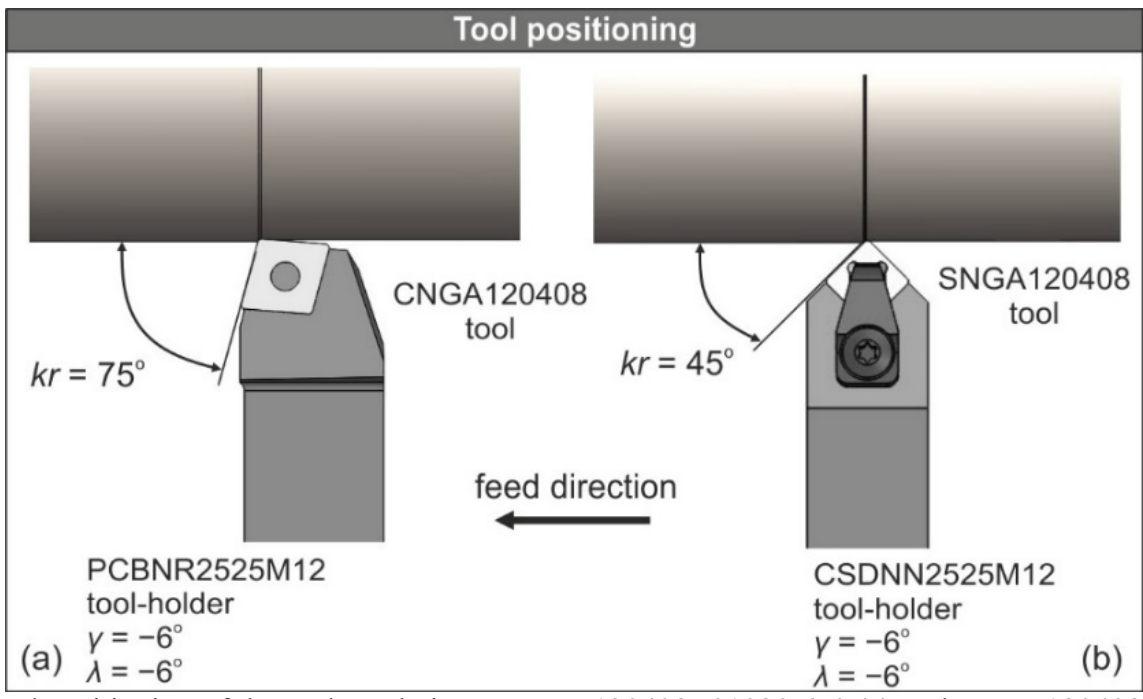

Fig. 1 CAD-based positioning of the tool-workpiece; CNGA120408T01020 650 (a) and SNGA120408T01020 650 (b)

\subsection{Turning process simulation setup}

Two sets, each comprising of nine 3D simulation tests, were carried out with DEFORM-3D ${ }^{\mathrm{TM}}$ ver. 12. In order to achieve reasonable simulation times, several simplifications were made. For instance, the model of the workpiece was designed as a part of the cylindrical bar instead of a full cylindrical piece, specifically it was designed as an arc with a diameter of $72 \mathrm{~mm}$ and an angle of $20^{\circ}$ (Figure 2(a)). Furthermore, a pre-cut surface was added, based on the used depth of cut (Figure 2(b)), further optimizing simulation times. The model was set to have plastic behavior and was meshed with about 32,000 to 46,000 tetrahedral elements depending on the value of feed. However, the contact interface between the cutting edge of the tool and the workpiece's uncut surface was refined with a denser mesh using a 7:1 size ratio (Figure 2(b)). In contrast, the tool was designed as fully rigid and the mesh was kept to a minimum size. Even though the mesh size of the tool models is not very significant compared to the one of the workpiece models, a refined mesh was applied near the tool tip also. Figure 2(c) illustrates the meshed models of the used inserts and highlights the refined area of the cutting edge where a 4:1 mesh size ratio was applied.

The cutting trajectory, as well as the vectors of the developed machining components, the tangential $\left(F_{t}\right)$, the radial $\left(F_{r}\right)$ and the feed $\left(F_{a}\right)$, are illustrated in Figure 2(a). 
The generalized Johnson and Cook's flow stress model [7] was employed in the present numerical study. It is commonly used for stress analysis in situations involving high strain, strain rate and temperatures. Equation 1 represents the formula of the aforementioned model. The material constants for the model are available in the literature. Equation 1 is divided into three parts; first part represents the strain hardening properties, second part the strain sensitivity and the last one, the thermal softening properties of the material. Where $A$ is the initial yield stress, $B$ is the strain hardening modulus, $C$ is the strain rate dependence coefficient, $\varepsilon$ stands for the plastic strain, $n$ stands for the strain hardening exponent, $m$ stands for the thermal softening coefficient, $\dot{\varepsilon}$ denotes the plastic strain rate, $\varepsilon_{0}$ denotes the reference plastic strain rate, $T$ represents the reference temperature, $T_{0}$ represents the bulk temperature and $T_{m}$ stands for the melting temperature of the workpiece material. The reference strain rate was set to $1 / \mathrm{s}$ in this study.

$$
\sigma=\left(A+B \varepsilon^{n}\right)\left(1+C \ln \frac{\dot{\varepsilon}}{\dot{\varepsilon}_{0}}\right)\left[1-\left(\frac{T-T_{0}}{T_{m}-T_{0}}\right)^{m}\right]
$$

Table 1 includes the basic properties of the AISI-D3 tool steel, whereas Table 2 the used material constants that describe the mechanical behaviour of the material for this model.

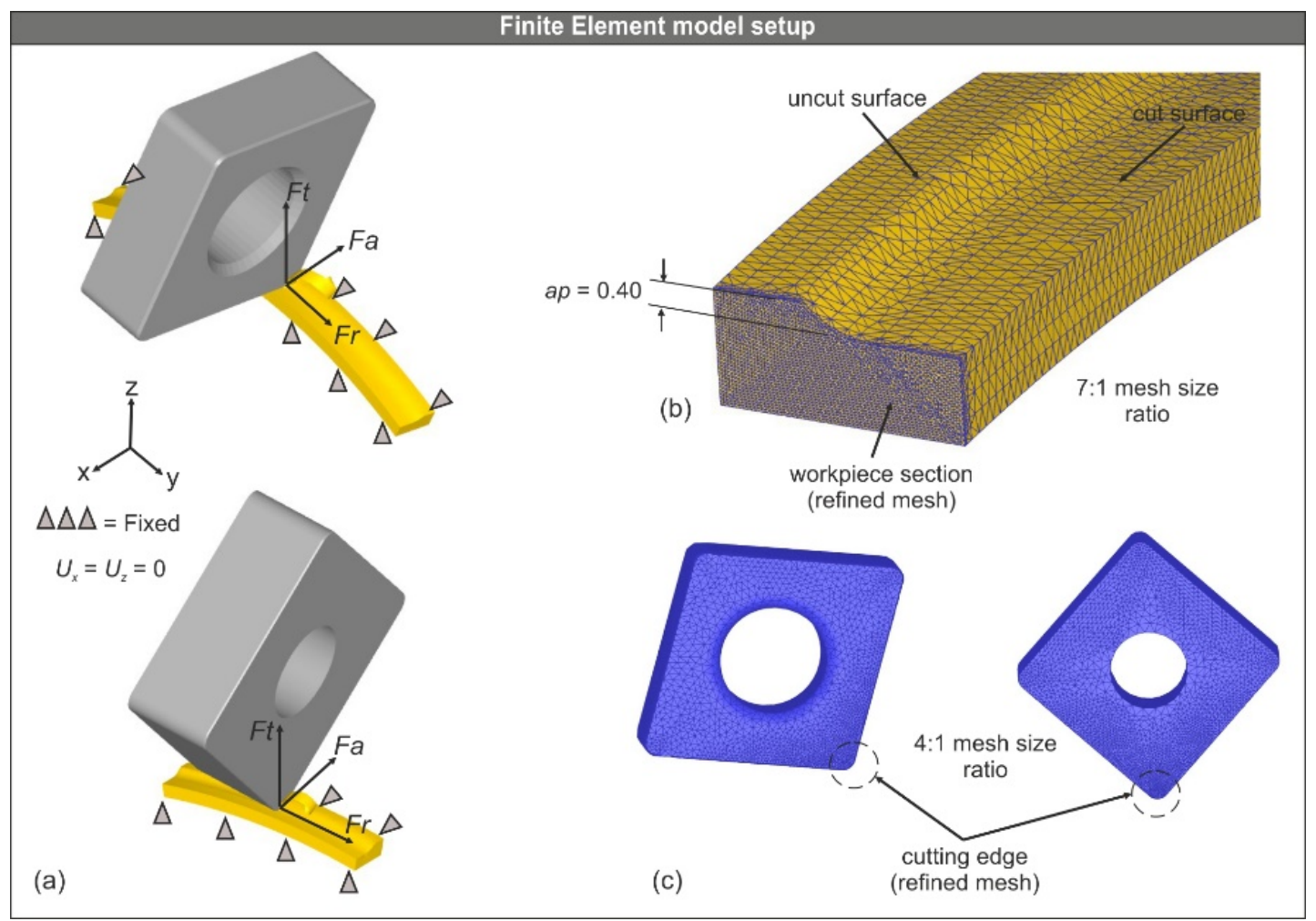

Fig. 2. 3D setup of the turning process; the cutting trajectory and the developed forces (a), the meshed workpiece (b) and the meshed tools (c)

Table 1. Basic thermo-mechanical properties of AISI-D3 [8]

\begin{tabular}{|c|c|c|c|c|}
\hline \multicolumn{5}{|c|}{ AISI-D3 properties } \\
\hline $\begin{array}{c}\text { Young's } \\
\text { modulus [GPa }]\end{array}$ & $\begin{array}{c}\text { Density } \\
{\left[\mathrm{kg} / \mathrm{m}^{3}\right]}\end{array}$ & $\begin{array}{c}\text { Poisson's } \\
\text { ratio }\end{array}$ & $\begin{array}{c}\text { Thermal } \\
\text { expansion } \\
{\left[\mu \mathrm{m} / \mathrm{m}^{\circ} \mathrm{C}\right]}\end{array}$ & $\begin{array}{c}\text { Thermal conductivity } \\
{[\mathrm{W} / \mathrm{mK}]}\end{array}$ \\
\hline & 7700 & 0.30 & 12 & $\begin{array}{c}50.71 \text { at } 100^{\circ} \mathrm{C} \\
45.69 \text { at } 300^{\circ} \mathrm{C} \\
33.94 \text { at } 600^{\circ} \mathrm{C}\end{array}$ \\
\hline
\end{tabular}

Table 2. Model constants of AISI-D3 [8]

\begin{tabular}{|c|c|c|c|c|c|c|}
\hline \multicolumn{7}{|c|}{ Constitutive model } \\
\hline$A[\mathrm{MPa}]$ & $B[\mathrm{MPa}]$ & $C$ & $n$ & $m$ & $T_{0}\left[{ }^{\circ} \mathrm{C}\right]$ & $T_{m}\left[{ }^{\circ} \mathrm{C}\right]$ \\
\hline 1985.6 & 193 & 0.1524 & 0.2768 & 0.2852 & 20 & 1421 \\
\hline
\end{tabular}


Modelling the material separation process due to the extreme contact pressure developed between the workpiece and the tool was realized with the use of the normalized Cockcroft and Latham criterion [7]. To describe the friction between the contact surfaces, the Coulomb's friction model was utilized. The friction coefficient for the present study was set to 0.6. This model is based on the assumption that the frictional stresses can be calculated with the use of a constant. Due to the simplicity of the model and the fact that it is widely used in similar conditions, it was selected for the purposes of the presented tests.

Finally, the boundary conditions for the toolworkpiece interface were set according to Figure 2. The workpiece was fixed in both $\mathrm{X}$ and $\mathrm{Z}$ axis, whereas the tool was set to move across the cutting path (Figure 2(a)), enabling this way the removal of material. The heat exchange between the tool, the workpiece and the environment was also defined. It was assumed that heat can be transferred over all surfaces via both convection and conduction with the default coefficient values.

\section{RESULTS AND DISCUSSION}

In order to compare the machining performance of the two inserts, two sets of numerical tests were performed. Each set contains identical tests according to the next cutting conditions; the depth of cut was kept at $a p=0.40 \mathrm{~mm}$ for all runs, the cutting speed varied between $V_{c}=75 \mathrm{~m} / \mathrm{min}, \quad V_{c}=110 \mathrm{~m} / \mathrm{min}$ and $V_{c}=140 \mathrm{~m} / \mathrm{min}$ and finally three levels of feed were used, $f=0.12 \mathrm{~mm} / \mathrm{rev}, \quad f=0.16 \mathrm{~mm} / \mathrm{rev} \quad$ and $f=0.20 \mathrm{~mm} / \mathrm{rev}$ accordingly. The simulation runs of the present investigation can be seen in Table 3 .

The machining performance of the tools in this investigation, derives by the produced cutting forces and temperature distribution. Obtained results were smoothened by applying the first order exponential smoothing and then were processed with a spreadsheet software. Figure 3 illustrates the comparison between the developed machining forces for the CNGA and SNGA tools.

Table 3. Standard order of the numerical tests

\begin{tabular}{|c|c|c|c|}
\hline Run & $V_{c}[\mathrm{~m} / \mathrm{min}]$ & $f[\mathrm{~mm} / \mathrm{rev}]$ & $a p[\mathrm{~mm}]$ \\
\hline 1 & 75 & 0.12 & 0.40 \\
\hline 2 & 75 & 0.16 & 0.40 \\
\hline 3 & 75 & 0.20 & 0.40 \\
\hline 4 & 110 & 0.12 & 0.40 \\
\hline 5 & 110 & 0.16 & 0.40 \\
\hline 6 & 110 & 0.20 & 0.40 \\
\hline 7 & 140 & 0.12 & 0.40 \\
\hline 8 & 140 & 0.16 & 0.40 \\
\hline 9 & 140 & 0.20 & 0.40 \\
\hline
\end{tabular}

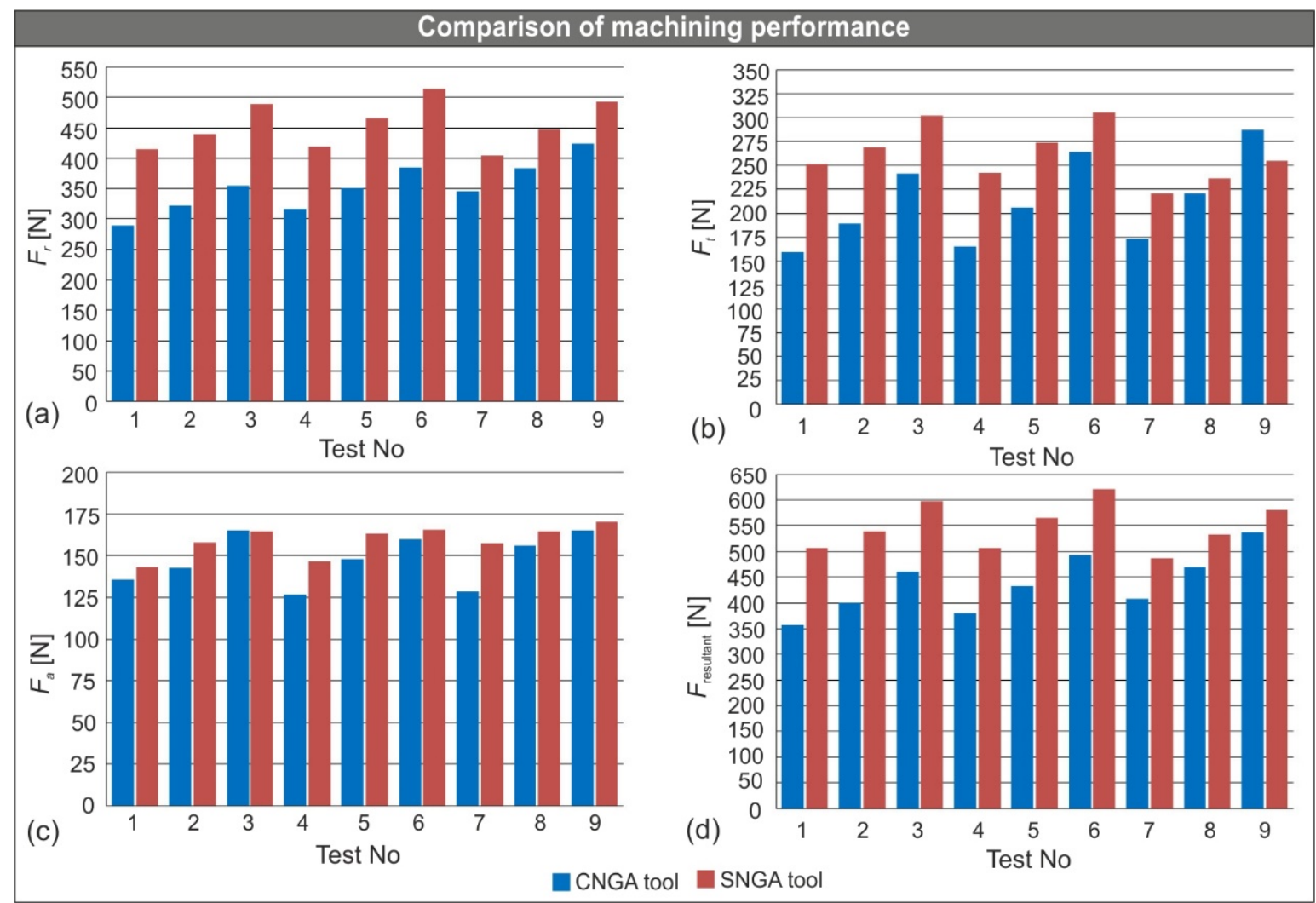

Fig. 3. Comparison of the developed machining forces; radial force (a), tangential force (b), feed force (c) and the resultant of the three components $(\mathrm{d})$ 
Specifically, Figure 3 visualizes the performance of the tools in terms of the developed cutting forces. Figure 3(a) shows the comparison between the results for the radial force, Figure 3(b) for the tangential force, Figure 3(c) for the feed force and finally Figure 3(d) for the resultant of the three components.

According to Figure 3, it is clear that the cutting forces developed when machining AISI-D3 with the SNGA tool are higher compared to the ones produced with the CNGA tool. Feed force is the exception, which ranges at approximately the same values for both tools. Moreover, it is noted that the radial force is the dominant component for both cases. Finally, by observing Figure 3(d), the next conclusions can be made:

- The average percentage of increase is close to $26.4 \%$.

- The percentage value decreases as feed increases.

- For a constant feed value, the increase percentage drops as higher values of cutting speed are used.

In addition to the cutting forces, the temperature distribution on the workpiece was also investigated.

Figure 4 illustrates sample distribution patterns for different cases. Figure 4(a) and 4(c) correspond to the CNGA tool, whereas Figure 4(b) and 4(d) correspond to the SNGA tool. It is noted that the temperature distribution pattern for the CNGA cases, spreads to a larger area compared to the SNGA cases. Despite this fact, the maximum temperature is approximately the same for both tools at identical cutting conditions. In addition, maximum temperature is generated on the contact surface between the tool-tip and the workpiece and it is found that the CNGA tool produces a wider chip, thus a wider area with the maximum temperature. This is expected due to the fact that increasing the lead angle $k r$, increases the chip contact length. Moreover, the generated chip have temperatures between $370^{\circ} \mathrm{C}$ and $515^{\circ} \mathrm{C}$ for both tools, at $80 \mathrm{~m} / \mathrm{min}$ cutting speed and $0.20 \mathrm{~mm} / \mathrm{rev}$ feed. Similarly, chip temperatures vary between $400^{\circ} \mathrm{C}$ and $560^{\circ} \mathrm{C}$ for both tools, at $110 \mathrm{~m} / \mathrm{min}$ cutting speed and $0.16 \mathrm{~mm} / \mathrm{rev}$ feed.

In order to be able to examine the validity of the models, a comparison was made with results from the bibliography. Similar studies for hard turning of AISI-4140 [6, 7, 11] and AISI-D3 [8] with the use of ceramic inserts, at similar cutting conditions, present results for the cutting forces, which are of the same magnitude with the results of the present study.

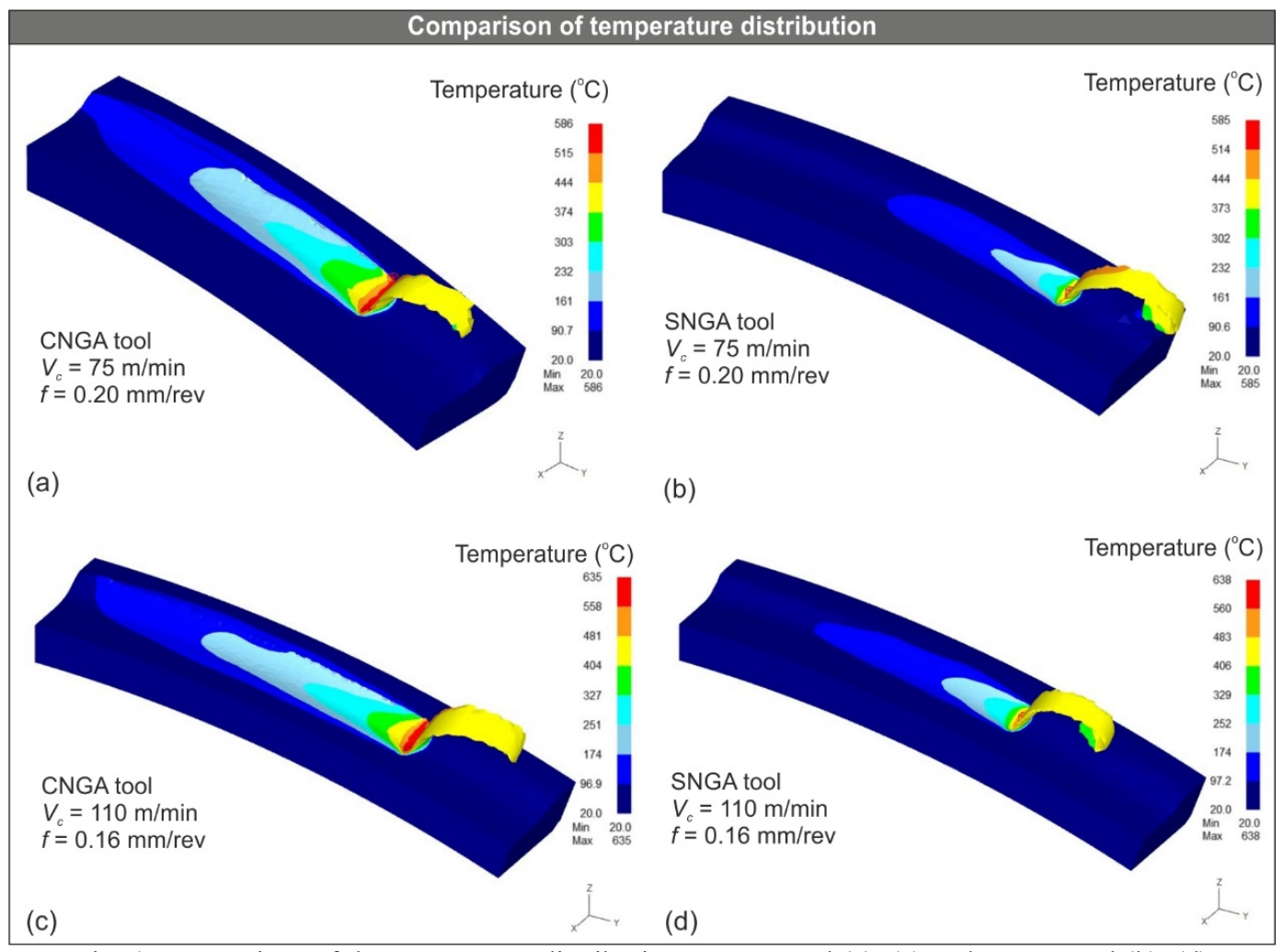

Fig. 4. Comparison of the temperature distribution; CNGA tool (a), (c) and SNGA tool (b), (d)

\section{CONCLUSIONS}

Eighteen numerical tests were performed in three dimensions with the aid of a commercially-available
FEA software. The tests refer to turning of AISI-D3 with rhombic and square inserts at cutting conditions that are recommended by tool manufacturers. The selected cutting conditions include cutting speed of 
$75 \mathrm{~m} / \mathrm{min}, 110 \mathrm{~m} / \mathrm{min}$ and $140 \mathrm{~m} / \mathrm{min}$, feed of $0.12 \mathrm{~mm} / \mathrm{rev}, 0.16 \mathrm{~mm} / \mathrm{rev}$ and $0.20 \mathrm{~mm} / \mathrm{rev}$, as well as depth of cut equal to $0.40 \mathrm{~mm}$. The yielded numerical results were compared with equivalent work that is available in the bibliography. The analysis of the performance of the tools, can be used to draw next conclusions:

-Radial force is the component that affects the most the resultant cutting force, for both tools.

-The developed machining forces are higher when using square inserts, with the exception of the feed force, which is about the same for both cases. The average percentage of this increase is about $26.4 \%$.

-Increasing cutting speed decreases the percentage of increase, the same effect applies when feed increases aswell.

-The temperature distribution seems to be spread to a larger surface when rhombic tools are used, compared to the cases where square tools are used.

Finally, both rhombic and square inserts produce approximately the same temperatures, for identical cutting conditions. This applies to both workpiece and chip temperatures.

\section{REFERENCES}

1. Davim JP, Maranhão C (2009) Study on plastic strain and plastic strain rate in machining of steel AISI 1020 using FEM analysis. Mater Des 30:160165. https://doi.org/10.1016/j.matdes.2008.04.029

2. Fang G, Zeng P (2007) FEM investigation for orthogonal cutting process with grooved toolstechnical communication. Mach Sci Technol 11:561572. https://doi.org/10.1080/10910340701731943

3. Tzotzis A, García-Hernández C, Huertas-Talón JL, Kyratsis P (2020) FEM based mathematical modelling of thrust force during drilling of Al7075T6. Mech Ind 21:1-14. https://doi.org/https://doi.org/10.1051/meca/2020046

4. Tzotzis A, Markopoulos A, Karkalos N, Kyratsis P (2020) 3D finite element analysis of Al7075-T6 drilling with coated solid tooling. MATEC Web of Conferences.

318:1-6. https://doi.org/10.1051/matecconf/202031801038

5. Tzotzis A, Markopoulos AP, Karkalos NE, Tzetzis D, Kyratsis P (2021) FEM based investigation on thrust force and torque during A17075-T6 drilling. IOP Conf Ser Mater Sci Eng 1037:012009. https://doi.org/10.1088/1757-899x/1037/1/012009

6. Tzotzis A, García-Hernández C, Huertas-Talón JL, Kyratsis P (2020) Influence of the Nose Radius on the Machining Forces Induced during AISI-4140 Hard Turning: A CAD-Based and 3D FEM Approach. Micromachines 11:1-16. https://doi.org/https://doi.org/10.3390/mi11090798
7. Tzotzis A, García-Hernández C, Huertas-Talón JL, Kyratsis P (2020) 3D FE Modelling of Machining Forces during AISI 4140 Hard Turning. Strojniški Vestn - J Mech Eng 66:467-478. https://doi.org/10.5545/sv-jme.2020.6784

8. Kyratsis P, Tzotzis A, Markopoulos A, Tapoglou N (2021) CAD-Based 3D-FE Modelling of AISI-D3 Turning with Ceramic Tooling. Machines 9:1-14. https://doi.org/10.3390/machines 9010004

9. Nasulea D, Oancea G (2021) Influence of DC05 deep drawing steel real material properties on numerical simulation of incremental forming process. IOP Conf Ser Mater Sci Eng 1009:1-8. https://doi.org/10.1088/1757-899X/1009/1/012041

10. Nasulea D, Oancea G (2018) Integrating a New Software Tool Used for Tool Path Generation in the Numerical Simulation of Incremental Forming Processes. Strojniški Vestn - J Mech Eng 64:643651. https://doi.org/10.5545/sv-jme.2018.5475

11.Tzotzis A, García-Hernández C, Huertas-Talón JL, Kyratsis P (2020) CAD-Based Automated Design of FEA-Ready Cutting Tools. J Manuf Mater Process 4:1-14.

https://doi.org/https://doi.org/10.3390/jmmp4040104
Received: September 11, 2021 / Accepted: December 15, 2021 / Paper available online: December 20, 2021 (C) International Journal of Modern Manufacturing Technologies. 